\title{
Image Retrieval and Classification Method Based on Euclidian Distance Between Normalized Features Including Wavelet Descriptor
}

\author{
Kohei Arai ${ }^{1}$ \\ Graduate School of Science and Engineering \\ Saga University \\ Saga City, Japan
}

\begin{abstract}
Image retrieval method based on Euclidian distance between normalized features with their mean and variance in feature space is proposed. Effectiveness of the normalization is evaluated together with a validation of the proposed image retrieval method. The proposed method is applied for discrimination and identifying dangerous red tide species based on wavelet utilized classification methods together with texture and color features. Through experiments, it is found that classification performance with the proposed wavelet derived shape information extracted from the microscopic view of the phytoplankton is effective for identifying dangerous red tide species among the other red tide species rather than the other conventional texture, color information. Moreover, it is also found that the proposed normalization of features is effective to improve identification performance.
\end{abstract}

Keywords-hue feature; texture information; wavelet descripter; red tide; phytoplankton idintification

\section{INTRODUCTION}

The conventional image retrieval methods use the color information such as $\mathrm{HSV}^{1}$ : Hue, Saturation and Value (Intensity), RGB: Red, Green, and Blue, etc. as the spectral information. Meanwhile texture information is also used in conventional image retrieval methods as the spatial information. On the other hand, Bachattarian [1], Euclidian ${ }^{2}$, Mahalanobis ${ }^{3}$ distance measures [2] are well known as the similarity or distance measure. Not only hierarchical ${ }^{4}$ and nonhierarchical clustering ${ }^{5}$ as well as Bayesian rule of classification $^{6}$ and Maximum Likelihood classification ${ }^{7}$, but also Vector quantization ${ }^{8}$, Support vector machine ${ }^{9}$, etc. are proposed and used for image retrievals. Relational information such as the relations among image portions or segments,

\footnotetext{
${ }^{1}$ http://www.cs.rit.edu/ ncs/color/t_convert.html

${ }^{2}$ http://en.wikipedia.org/wiki/Euclidean_distance

${ }^{3}$ http://en.wikipedia.org/wiki/Mahalanobis_distance

${ }^{4}$ http://en.wikipedia.org/wiki/Hierarchical_clustering

${ }^{5}$ http://www.daylight.com/meetings/mug96/barnard/E-MUG95.html

${ }^{6} \mathrm{http}: / /$ en.wikipedia.org/wiki/Naive_Bayes_classifier

${ }^{7}$ http://www.ccrs.nrcan.gc.ca/glossary/index_e.php?id=341

${ }^{8}$ http://en.wikipedia.org/wiki/Learning_Vector_Quantization

${ }^{9}$ http://en.wikipedia.org/wiki/Support_vector_machine
}

semantic information, knowledge based information, relational similarity to classify semantic relations [3] etc. are tried to use in image retrievals. Spatial and spectral information derived from the images in concern is applicable image retrievals. There are some moment based spatial information extraction methods [4], [5], texture feature based spatial information extraction methods [6] and spectral information based image retrieval methods [7], [8], [9]. Furthermore, some attempts are made for image retrievals with wavelet descriptor as a spatial information extraction [9], [10]. In general, these conventional methods have not so good performance in terms of retrieval success rate.

Image retrieval method based on texture, hue and shape features is proposed [11]. In the proposed method, texture feature is extracted based on discrete wavelet transformation while shape feature is extracted by the proposed wavelet descriptor which allows extraction and representation of contour [12]. Contour of the object extracted from the original image can be expressed with wavelet based descriptor. The image retrieval method which is based on the hue information and texture as well as the wavelet described shape information of extracted objects is proposed previously to improve image retrieval success rate. Image retrieval performance is not good enough in particular for resemble red tide species. The method proposed here is normalization of features in concern with their mean and variance. Through the normalization, all the features used should have almost same influence for discrimination between the current specie and the referenced specie results in improvement of identification performance.

The following section describes the proposed image retrieval method followed by some experiments for reproducibility of the proposed wavelet descriptor in comparison to the conventional Fourier descriptor with several simple symmetrical and asymmetrical shapes. Then it is validated with the image database of phytoplankton [13].

\section{PROPOSED Method}

\section{A. Process Flow of the Proposed Image Classification}

Image classification method based on hue information [14] and wavelet description based shape information [15] as well as texture information of the objects extracted with dyadic wavelet transformation [16] is proposed. Object is assumed to be focused so that the frequency component in the object is 
relatively high in comparison to the other (background). Figure 1 shows the process flow of the proposed image classification method.

One of the image features of hue information (angle) is calculated for the entire image in the color image database. Dyadic wavelet transformation ${ }^{10}$ is also applied to the images then texture information is extracted from the transformed resultant image. Based on the Dyadic wavelet transformation, $\mathrm{HH}^{11}$ image of edge is extracted from the original image. Morphological operations ${ }^{12}$, opening and closing are then applied to the edge extracted images to remove inappropriate isolated pixels and undesirable image defects. After that the resultant image is binarized with appropriate threshold then contour of the object is extracted. Then the Dyadic wavelet transformation is applied to the contour in order to extract shape information (Wavelet descriptor). After all, Euclidian distance between target image and the other candidate images in the color image database is calculated with extracted hue, texture and shape information then the closest image is retrieved.

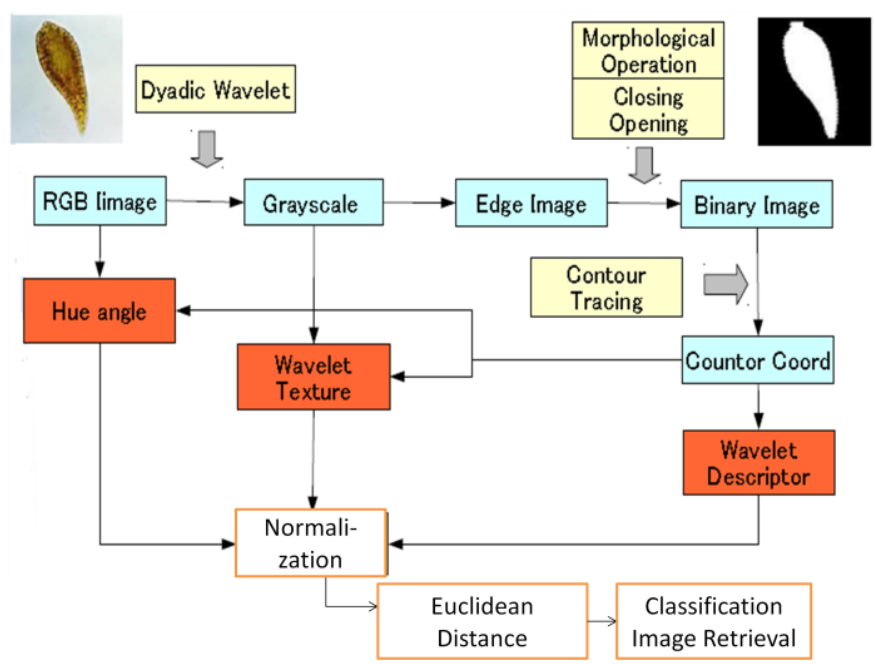

Fig. 1. Process flow of the proposed image classification method.

Normalization of the extracted features is applied in the proposed method. Then image in concern is retrieved with Euclidian distance between features of the image in concern and the images in the given image database.

\section{B. Dyadic wavelet transformation}

Using dyadic wavelet, frequency component can be detected. Dyadic wavelet allows to separate frequency components keeping image size with that of original image. Dyadic wavelet is called as a binary wavelet and has high pass

10

http://cas.ensmp.fr/ chaplais/Wavetour_presentation/ondelettes\%20dyadiques /Dyadic_Transform.html

${ }^{11} \mathrm{HH}$ denotes high frequency component in horizontal direction and high frequency component in vertical direction

${ }^{12}$ http://geol.hu/data/online_help/MorphologyFilters.html and low pass filter components, $\{\mathrm{h}[\mathrm{k}], \mathrm{g}[\mathrm{k}]\}$ and reconstruction filter $\{\underline{\mathrm{h}}[\mathrm{k}], \mathrm{g}[\mathrm{k}]\}$. Low and high frequency components, $\mathrm{C}_{\mathrm{n}}$ and $\mathrm{d}_{\mathrm{n}}$ are expressed as follows,

$$
\begin{aligned}
& C_{n}[i]=\Sigma_{k} h[k] C_{n-1}\left[i+k 2^{n-1}\right] \\
& d_{n}[i]=\Sigma_{k} g[k] C_{n-1}\left[i+k 2^{n-1}\right]
\end{aligned}
$$

Then original image is also reconstructed with the low and high frequency components as follows,

$$
C_{n-1}[i]=1 / 2 \Sigma_{k} \underline{h}[k] C_{n}\left[i-k 2^{n-1}\right]+\Sigma_{k} g[k] d_{n}\left[i-k 2^{n-1}\right]
$$

If a new parameter $\mathrm{s}[\mathrm{m}]$ is employed, then lifting dyadic wavelet is defined as follows,

$$
\begin{aligned}
& h^{\text {new }}[k]=h^{\text {old }}[k] \\
& \underline{h}^{\text {new }}[k]=\underline{h}^{\text {old }}[k]+\Sigma_{m} s[-m] g^{\text {old }}[k-m] \\
& \left.g^{\text {new }}[k]\right]=g^{\text {old }}[k]-\Sigma_{m} s[m] h^{\text {old }}[k-m] \\
& g^{\text {new }}[k]=g^{\text {old }}[k]
\end{aligned}
$$

\section{Dyadic wavelet based descriptor (Shape information)}

Image classification method with hue and texture information is conventional. In the proposed method, another feature, shape information is employed. Fourier descriptor is used, in general, to represent shape information. Although Fourier descriptor represents frequency component of the contour line, location information cannot be described. In other words, Fourier descriptor does support only frequency analysis, and does not support time-frequency component analysis. Wavelet descriptor which is proposed by this paper supports a time-frequency component analysis so that not only frequency component but also location of contour edge can be discussed [17].

Let $\mathrm{u}(\mathrm{i})$ be distance between a point in the closed object contour line and a certain point $i$ on the line, then the closed object contour line can be represented as $u(i), i=1,2, \ldots, n$. $i=1$ corresponds to 0 degree while $i=n$ corresponds to 360 degree, respectively. u(i) can be converted with dyadic wavelet transformation. Then the contour line can be represented with high frequency component of the dyadic wavelet transformed sequence as is shown in Figure 2. Then average of the high frequency component of pixel value is used for a feature of the image classification.

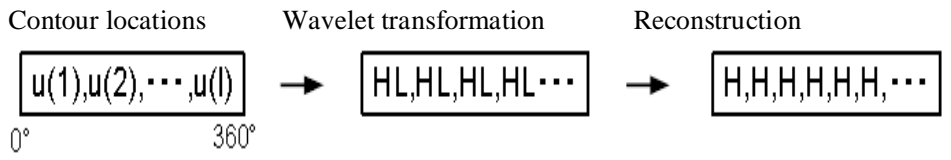

Fig. 2. Dyadic wavelet descriptor for representation of the closed object contour lines.

\section{Texture Feature}

Also texture information is useful for discrimination. Texture information can be derived from dyadic wavelet transformation. Texture information is defined as high frequency component of pixel value derived from dyadic wavelet transformation. Daubechies wavelet transformation is applied to the $2 \times 2$ pixels defined in Figure 3. 


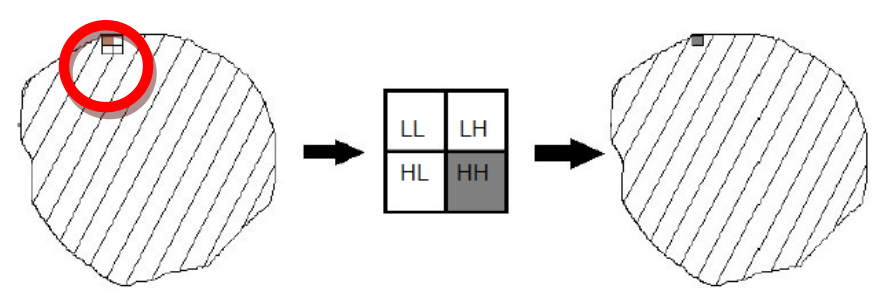

Fig. 3. Detected object and $2 \times 2$ of matrix in the object to detect texture information with $2 \times 2$ of dyadic wavelet transformation.

Pixel value of the pixel in the object is replaced to the high frequency component detected with Daubechies wavelet. Thus image which represents texture information of the detected object image is generated [18]. Daubechies base function of wavelet has order. 1 st order of Daubechies base function is totally equal to Haar base function. In this paper, 1st, 2nd,4 th order of Daubechies base function is used and compare their classification and image retrieval performance with Euclidean distance between the specified phytoplankton and the others.

\section{E. Hue angle}

Thus contour of the object is detected. Then Red, Green, and Blue: RGB of the original object image can be transformed to Hue, Saturation, and Intensity: HSV information. Hue information in unit of radian, in particular, is useful for discrimination of the target image classifications of phytoplankton images.

RGB to HSV conversion is also be expressed as follows,

$$
\begin{gathered}
V=\max (R, G, B) \\
S=(V-X) / V \text { where } X=\min (R, G, B) \\
R=V: H=(\pi / 3)(b-g) \\
G=V: H=(\pi / 3)(2+r-b) \\
B=V: H=(\pi / 3)(4+g-r)
\end{gathered}
$$

where $r=(V-R) /(V-X), g=(V-G) /(V-X), b=(V-$ $B) /(V-X), H$ ranges from 0 to $360, S$ ranges from 0 to $1, V$ ranges from 0 to $1, \mathrm{HSV}$ representation and $\mathrm{R}, \mathrm{G}, \mathrm{B}$ also range from 0 to 1 .

These three features, hue, $H$, texture, $x x$ and shape information, $y y$ composes three dimensional feature space results in measurement of Euclidian distance between a query image and the images in previously created image database. Using the distance, a query image can be retrieved from the image in the database. Thus image classifications can be done with hue and texture information as well as shape information derived from dyadic wavelet descriptor.

\section{EXPERIMENTS}

\section{A. Data Used}

There are a plenty of red tide species. Small portion of red tide species can be listed up in Figure 1. These red tide species can be classified into three categories, (a) Caution level of species, (b) Warning level of species, and (c) Dangerous species. Fishes and shells take these dangerous red tide species. After that human habitats eat the fishes and shells. Then such persons get a bad situation and have an illness condition. Therefore, these red tide species are classified into dangerous species.

Identifying these dangerous red tide species is important. It, however, is not so easy to classify because these three categories of red tide species are quite resemble. Usually, the local fishery research institutes measure red tide from the research vessels with microscope. They used to count the number of red tide with microscope camera acquired imagery data on the ship. Then identify the red tide species in the same time quickly. Even though human perception capability is superior to that by machine learning based automatic classification, there are some mistakes. The purpose of the research is to improve classification performance by using considerable features which can be extracted from the microscopic imagery data.

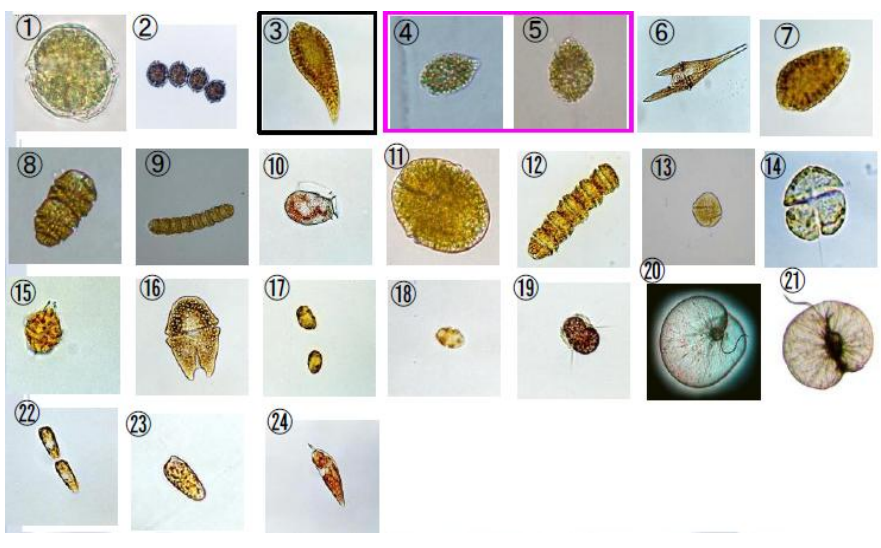

Fig. 4. Photos of a portion of red tide species

B. Comparison of Euclidian Distance Between Cahttnella Antiqua-3 and the Others with Three Features, Texture, Hue and Wavelet Discriptor Based on Daubechies 1, 2, and 4

One of the measures for classification performance evaluation is Euclidian distance among the classes in concern. Shorter Euclid distance implies a poor classification performance while longer distance means a good performance.

Euclid distance between Chattnella_Antiqua-3 and the other species are calculated and shown in Table 1, 2, 3 for the case of utilizing all these three features of wavelet descriptor with Daubechies 1, 2, and 4, respectively. Calculated Euclid Distance when Texture Wavelet Descripter and hue information are used as features. 
TABLE I. EUCLID DISTANCE BETWEEN CHATTNELLA ANTIQUA3 AND THE OTHERS WITH DAUBECHIES 1

\begin{tabular}{|c|c|c|c|c|c|c|c|c|c|}
\hline \multirow[t]{2}{*}{ Daubechies 1} & \multicolumn{3}{|l|}{ Mean } & \multicolumn{3}{|c|}{ Normalized Mean } & \multicolumn{3}{|c|}{ Euclid Distance } \\
\hline & wavelet & texture & hue(rad) & wavelet & texture & hue(rad) & Normalized & Mean & \%Improve \\
\hline a.catenella1cell & 0.196484 & 4.320291 & 1.29206 & 4.320291 & 5.208882 & 3.47149 & 2.610026 & 0.730394 & 257.3451 \\
\hline a.catenella4cell & 0.263178 & 5.48481 & 3.647233 & 5.48481 & 12.68603 & 5.002298 & 8.867848 & 3.258216 & 172.1688 \\
\hline c.antiqua & 0.283669 & 5.571536 & 0.892777 & 5.571536 & 3.941248 & 5.472623 & 1.887694 & 1.870292 & 0.930425 \\
\hline c.antiqua2 & 0.288699 & 3.577128 & 2.054994 & 3.577128 & 7.631026 & 5.588075 & 3.60677 & 1.141521 & 215.9618 \\
\hline c.antiqua3 & 0.29426 & 3.701602 & 0.920312 & 3.701602 & 4.028665 & 5.715715 & 0 & 0 & 0 \\
\hline c.furca & 0.246901 & 8.065513 & 1.742646 & 8.065513 & 6.639391 & 4.628697 & 5.200117 & 4.440745 & 17.1001 \\
\hline c.marina & 0.222682 & 3.65 & 0.779962 & 3.65 & 3.583085 & 4.072805 & 1.703043 & 0.183073 & 830.2522 \\
\hline c.polykrikoides 2 cell & 0.24923 & 3.70454 & 1.181714 & 3.70454 & 4.858558 & 4.682154 & 1.325511 & 0.271051 & 389.0264 \\
\hline c.polykrikoides8cell & 0.217637 & 3.961787 & 1.173258 & 3.961787 & 4.831712 & 3.957009 & 1.950802 & 0.364634 & 435.0023 \\
\hline d.fortii & 0.327144 & 9.655471 & 1.421595 & 9.655471 & 5.620126 & 6.470492 & 6.208945 & 5.975446 & 3.90763 \\
\hline g.catenatum1cell & 0.210512 & 4.233059 & 0.83791 & 4.233059 & 3.767057 & 3.79347 & 2.011445 & 0.544842 & 269.1797 \\
\hline g.catenatum5cell & 0.230301 & 8.044559 & 0.789282 & 8.044559 & 3.612674 & 4.247682 & 4.603199 & 4.345976 & 5.918657 \\
\hline g.instriatum & 0.411956 & 4.286565 & 1.57805 & 4.286565 & 6.116836 & 8.417158 & 3.464165 & 0.896759 & 286.2983 \\
\hline g.mikimotoi & 0.256012 & 5.721647 & 2.321516 & 5.721647 & 8.477174 & 4.837819 & 4.963921 & 2.459018 & 101.866 \\
\hline g.polygramma & 0.295303 & 7.345761 & 1.019077 & 7.345761 & 4.342222 & 5.739655 & 3.657702 & 3.645502 & 0.334673 \\
\hline g.sanguineum & 0.27297 & 9.884615 & 1.184978 & 9.884615 & 4.86892 & 5.227051 & 6.258951 & 6.188811 & 1.13334 \\
\hline h.akashiwo & 0.550117 & 7.972222 & 0.993822 & 7.972222 & 4.262043 & 11.58833 & 7.265003 & 4.2888 & 69.39478 \\
\hline h.circularisquama & 0.499699 & 4.288433 & 0.850071 & 4.288433 & 3.805666 & 10.4311 & 4.756989 & 0.665326 & 614.9864 \\
\hline m.rubrum & 0.35107 & 7.850218 & 1.444111 & 7.850218 & 5.69161 & 7.019659 & 4.655821 & 4.182799 & 11.30874 \\
\hline n.scintillans4 & 0.225198 & 3.990742 & 2.205616 & 3.990742 & 8.109217 & 4.130554 & 4.387168 & 1.320164 & 232.3199 \\
\hline n.scintillans5 & 0.184937 & 2.872873 & 1.507892 & 2.872873 & 5.8941 & 3.206455 & 3.23466 & 1.026171 & 215.2166 \\
\hline Mean & 0.289427 & 5.62778 & 1.420899 & 5.62778 & 5.617916 & 5.604776 & 3.934275 & 2.276169 & 196.6501 \\
\hline Standard Deviation & 0.095136 & 2.183621 & 0.687803 & 2.183621 & 2.183621 & 2.183621 & 2.147732 & 1.994634 & 224.5983 \\
\hline
\end{tabular}

TABLE II. EUCLID DisTANCE BETWEEN CHATTNELLA ANTIQUA3 AND THE OTHERS WITH DAUBECHIES 2

\begin{tabular}{|c|c|c|c|c|c|c|c|c|c|}
\hline \multirow[t]{2}{*}{ Daubechies 2} & \multicolumn{3}{|l|}{ Mean } & \multicolumn{3}{|c|}{ Normalized Mean } & \multicolumn{3}{|c|}{ Euclid Disatance } \\
\hline & wavelet & texture & hue(rad) & wavelet & texture & hue(rad) & Normalized & Mean & \%Improve \\
\hline a.cat & 0.080995 & 4.320291 & 29206 & 4.320291 & 08882 & .705773 & 2.32756 & 394 & 218.672 \\
\hline a.cat & & 81 & & & 12.68603 & 414 & 8.841316 & 3.258216 & 171.3545 \\
\hline c.an & & 5.5 & 92777 & 5.571536 & 3.941248 & 5.128525 & 1.933937 & 1.870292 & 3.402932 \\
\hline c.ant & & 3.577128 & 2.054994 & 3.577128 & 7.631026 & & 3.608915 & 1.141521 & 216.1497 \\
\hline c.an & 180553 & 3.701602 & 0.920312 & 3.701602 & 4.028665 & 5.614136 & 0 & 0 & 0 \\
\hline c.furca & 0.159615 & 8.065513 & 1.742646 & 8.065513 & 6.639391 & 5.212789 & 5.101048 & 4.440745 & 14.86918 \\
\hline c.m & 0.085888 & 3.65 & 0.779962 & 3.65 & 3.583085 & 3.799564 & 1.869191 & 0.183073 & 0066 \\
\hline c.po & 0 & 70454 & 14 & 70454 & & 4.40883 & & 271051 & 3925 \\
\hline c.polyk & 0.147278 & 3.961787 & 1.173258 & 3.961787 & 4.831712 & 4.976309 & 1.058019 & 0.364634 & 190.1588 \\
\hline d.fortii & 0.236693 & 9.655471 & 1.421595 & 9.655471 & 5.620126 & 6.690247 & 6.256143 & 5.975446 & 4.697494 \\
\hline g.catenatu & 0.103167 & 4.233059 & 0.83791 & 4.233059 & 3.767057 & 4.130774 & 1.597262 & 0.544842 & 193.1609 \\
\hline g.catenatur & 0.098365 & 8.044559 & 0.789282 & 8.044559 & 3.612674 & 4.038728 & 4.63856 & 4.345976 & 6.732285 \\
\hline g.instriatum & 0.315118 & 4.286565 & 1.57805 & 4.286565 & 6.116836 & 8.193524 & 3.369849 & 0.896759 & 275.781 \\
\hline g.mikimotoi & 0.122712 & 5.721647 & 2.321516 & 5.721647 & 8.477174 & 4.505419 & 5.009897 & 2.459018 & 103.7357 \\
\hline g.polygramma & .16845 & 7.345761 & 1.019077 & 7.345761 & 4.342222 & 5.382141 & 3.664974 & 3.645502 & 0.534143 \\
\hline g.sanguineum & 0.134972 & & & 9.884615 & 4.86892 & 4.740423 & 6.300718 & 6.188811 & 1.808221 \\
\hline h.akashiwo & 0.503999 & 7.972222 & 0.993822 & 7.972222 & 4.262043 & 11.81406 & 7.532047 & 4.2888 & 75.62133 \\
\hline h.circularisquama & 0.429245 & 4.288433 & 0.850071 & 4.288433 & 3.805666 & 10.38115 & 4.808173 & 0.665326 & 622.6794 \\
\hline m.rubrum & 0.260962 & 7.850218 & 1.444111 & 7.850218 & 5.69161 & 7.155443 & 4.727793 & 4.182799 & 13.02941 \\
\hline n.scintillans 4 & 0.105809 & 3.990742 & 2.205616 & 3.990742 & 8.109217 & 4.181417 & 4.334419 & 1.320164 & 228.3243 \\
\hline n.scintillans5 & 0.053063 & 2.872873 & 1.507892 & 2.872873 & 5.8941 & 3.170363 & 3.184127 & 1.026171 & 210.2921 \\
\hline Mean & 0.181013 & 5.62778 & 1.420899 & 5.62778 & 5.617916 & 5.622949 & 3.887016 & 2.276169 & 186.2811 \\
\hline
\end{tabular}


\begin{tabular}{|l|l|l|l|l|l|l|l|l|l|} 
Standard Deviation & 0.113918 & 2.183621 & 0.687803 & 2.183621 & 2.183621 & 2.183621 & 2.233389 & 1.994634 & 233.1855 \\
\hline
\end{tabular}

TABLE III. EUCLID DisTANCE BETWEEN CHATTNELLA ANTIQUA3 AND THE OTHERS WITH DAUBECHIES 4

\begin{tabular}{|c|c|c|c|c|c|c|c|c|c|}
\hline \multirow[t]{2}{*}{ Daubechies 4} & \multicolumn{3}{|l|}{ Mean } & \multicolumn{3}{|c|}{ Normalized Mean } & \multicolumn{3}{|c|}{ Euclid Disatance } \\
\hline & wavelet & texture & ue(rad) & wavelet & texture & hue(rad) & Normalized & Mean & \%Improve \\
\hline a.cat & 0.08 & 4.2 & & 20291 & 882 & 761 & 2.237914 & 730394 & 984 \\
\hline a.cat & 94141 & 81 & 233 & 48481 & 12.68603 & 5.391889 & 8.839726 & 3.258216 & 171.3057 \\
\hline c.ant & 176529 & 5.571536 & 0.892777 & 5.571536 & 3.941248 & 5.10869 & 1.911765 & 1.870292 & 2.217423 \\
\hline c.anti & 0.192126 & 3.577128 & 2.054994 & 3.577128 & 7.631026 & 5.359488 & 3.607122 & 1.141521 & 215.9926 \\
\hline c.ant & 0.200659 & 3.701602 & 0.920312 & 3.701602 & 4.028665 & 5.496697 & 0 & 0 & 0 \\
\hline c.furca & 0.184336 & 5513 & 1.742646 & 55513 & 6.639391 & 5.234226 & 5.092004 & .440745 & 14.66552 \\
\hline c.marina & 0.095042 & 3.65 & 0.779962 & 3.65 & 3.583085 & 3.798392 & 1.756543 & 0.183073 & 859.4753 \\
\hline c.polykrikoides 2 cell & 0.129042 & 3.70454 & 1.181714 & 3.70454 & 4.858558 & 4.345107 & 1.419469 & 0.271051 & 423.6906 \\
\hline c.polykrikoides 8 cell & 0.164878 & 3.961787 & 1.173258 & 3.961787 & 4.831712 & 4.921344 & 1.021573 & 0.364634 & 180.1637 \\
\hline d.fortii & 0.278876 & 9.655471 & 1.421595 & 9.655471 & 5.620126 & 754414 & 6.289925 & 75446 & 5.26285 \\
\hline g.catenatum1cell & 0.113391 & 4.233059 & 83791 & 4.233059 & 3.767057 & 4.093441 & 1.523159 & 0.544842 & 5599 \\
\hline g.catenatum5cell & 0.105457 & 8.044559 & 0.789282 & 8.044559 & 3.612674 & 3.965864 & 4.623611 & 4.345976 & 8313 \\
\hline g.ins & 0 & & & & & & 3.506854 & .896759 & 0587 \\
\hline g.miki & & 5.721647 & & & & & & 2.459018 & 1.6897 \\
\hline g.polygramma & & & & & & & & & 0.365202 \\
\hline g.sanguineun & & & & & & & 6.274626 & 6.188811 & 1.386621 \\
\hline h.akashiwo & 0.588219 & 7.972222 & 0.993822 & 7.972222 & 4.262043 & & & 4.2888 & 76.23562 \\
\hline h.circularisg & 0.506198 & 4.288433 & 0.850071 & 4.288433 & 3.805666 & 10.40972 & 4.952965 & 0.665326 & 644.442 \\
\hline m.rubrum & 0.302785 & 7.850218 & 1.444111 & 7.850218 & 5.69161 & 7.138867 & 4.76163 & 4.182799 & 13.83836 \\
\hline n.scin & 0.11566 & 3.990742 & 2.205616 & 3.990742 & 8.109217 & 4.129926 & 4.31307 & 1.320164 & 226.7071 \\
\hline n.sc & 0.0558 & 2.872873 & 1.507892 & 2.872873 & 5.8941 & 3.167387 & 3.097148 & 1.026171 & 201.8161 \\
\hline Mean & 0.207911 & & & 5.62778 & 5.617916 & 5.613306 & 3.876471 & 2.276169 & 182.0314 \\
\hline Standard Deviation & 0.135799 & 2.183621 & 0.687803 & 2.183621 & 2.183621 & 2.183621 & 2.255699 & 1.994634 & 225.2163 \\
\hline
\end{tabular}

It is clear that the mean and standard deviation after the normalization are same in comparison to the before the normalization. It also found that the Euclidian distance between Chattnella Antiqua-3 and the others are improved remarkably, around twice much longer distance.

\section{Euclidian Distance Between Chattnella-3 and the Others}

Using Hue and Texture information as well as with and without Wavelet Discriptor

Effectiveness of the wavelet descriptor is evaluated through comparisons of Euclidian distance between Chattnella Antiqua-3 of specie and the other species calculated with the normalized features. Table 4, 5, 6 shows the results for Daubechies 1, 2, 4 of base function of wavelet.

The mean of Euclidian distance for without wavelet descriptor shows around 2.7 while that with wavelet descriptor shows more than 3.8. Therefore, effectiveness of wavelet descriptor is corresponding to $40 \%$ improvement of Euclidian distance which results in $40 \%$ improvement of image retrieval and classification.

TABLE IV. EUCLID DisTANCE BETWEEN CHATTNELLA ANTIQUA3 AND THE OTHERS WITH DAUBECHIES 1

\begin{tabular}{|c|c|c|}
\hline Daubechies 1 & With & Without \\
\hline & \multicolumn{2}{|c|}{ Wavelet Descriptor } \\
\hline a.catenella1cell & 2.610026 & 2.535638 \\
\hline
\end{tabular}

\begin{tabular}{|c|r|r|} 
a.catenella4cell & 8.867848 & 8.686708 \\
\hline c.antiqua & 1.887694 & 0.258332 \\
\hline c.antiqua2 & 3.60677 & 3.604622 \\
\hline c.antiqua3 & 0 & 0 \\
\hline c.furca & 5.200117 & 2.827985 \\
\hline c.marina & 1.703043 & 1.702262 \\
\hline c.polykrikoides2cell & 1.325511 & 1.325508 \\
\hline c.polykrikoides8cell & 1.950802 & 1.933373 \\
\hline d.fortii & 6.208945 & 1.761374 \\
\hline g.catenatum1cell & 2.011445 & 1.939965 \\
\hline g.catenatum5cell & 4.603199 & 1.525834 \\
\hline g.instriatum & 3.464165 & 3.414419 \\
\hline g.mikimotoi & 4.963921 & 4.534306 \\
\hline g.polygramma & 3.657702 & 0.314469 \\
\hline g.sanguineum & 6.258951 & 0.972019 \\
\hline h.akashiwo & 7.265003 & 5.87725 \\
\hline h.circularisquama & 4.756989 & 4.720654 \\
\hline m.rubrum & 4.655821 & 2.11321 \\
\hline n.scintillans4 & 4.387168 & 4.37763 \\
\hline n.scintillans5 & 3.23466 & 3.126697 \\
\hline Mean & 3.934275 & 2.740584 \\
\hline Standard Deviation & 2.147732 & 2.077256 \\
\hline
\end{tabular}


TABLE V. EUCLID DISTANCE BETWEEN CHATTNELLA ANTIQUA3 AND THE OTHERS WITH DAUBECHIES 2

\begin{tabular}{|c|c|c|}
\hline Daubechies 2 & With & Without \\
\hline & \multicolumn{2}{|l|}{ Wavelet Descriptor } \\
\hline a.catenella1cell & 2.32756 & 2.243827 \\
\hline a.catenella4cell & 8.841316 & 8.659621 \\
\hline c.antiqua & 1.933937 & 0.493416 \\
\hline c.antiqua2 & 3.608915 & 3.606767 \\
\hline c.antiqua3 & 0 & 0 \\
\hline c.furca & 5.101048 & 2.641396 \\
\hline c.marina & 1.869191 & 1.868478 \\
\hline c.polykrikoides 2 cell & 1.463384 & 1.463381 \\
\hline c.polykrikoides8cell & 1.058019 & 1.025528 \\
\hline d.fortii & 6.256143 & 1.921136 \\
\hline g.catenatum 1 cell & 1.597262 & 1.506254 \\
\hline g.catenatum5cell & 4.63856 & 1.629404 \\
\hline g.instriatum & 3.369849 & 3.31869 \\
\hline g.mikimotoi & 5.009897 & 4.584592 \\
\hline g.polygramma & 3.664974 & 0.39005 \\
\hline g.sanguineum & 6.300718 & 1.212189 \\
\hline h.akashiwo & 7.532047 & 6.204316 \\
\hline h.circularisquama & 4.808173 & 4.772227 \\
\hline m.rubrum & 4.727793 & 2.26738 \\
\hline n.scintillans4 & 4.334419 & 4.324765 \\
\hline n.scintillans5 & 3.184127 & 3.07439 \\
\hline Mean & 3.887016 & 2.724181 \\
\hline Standard Deviation & 2.233389 & 2.096728 \\
\hline
\end{tabular}

TABLE VI. EUCLID DISTANCE BETWEEN CHATTNELLA ANTIQUA3 AND THE OTHERS WITH DAUBECHIES 4

\begin{tabular}{|c|r|r|}
\hline Daubechies 4 & With & Without \\
\hline & \multicolumn{2}{|c|}{ Wavelet Descriptor } \\
\hline a.catenella1cell & 2.237914 & 2.150694 \\
\hline a.catenella4cell & 8.839726 & 8.657998 \\
\hline c.antiqua & 1.911765 & 0.397732 \\
\hline c.antiqua2 & 3.607122 & 3.604973 \\
\hline c.antiqua3 & 0 & 0 \\
\hline c.furca & 5.092004 & 2.623887 \\
\hline c.marina & 1.756543 & 1.755785 \\
\hline c.polykrikoides2cell & 1.419469 & 1.419465 \\
\hline c.polykrikoides8cell & 1.021573 & 0.987884 \\
\hline d.fortii & 6.289925 & 2.028448 \\
\hline g.catenatum1cell & 1.523159 & 1.427433 \\
\hline g.catenatum5cell & 4.623611 & 1.586348 \\
\hline g.instriatum & 3.506854 & 3.457722 \\
\hline g.mikimotoi & 4.959585 & 4.529559 \\
\hline g.polygramma & 3.658815 & 0.32716 \\
\hline g.sanguineum & 6.274626 & 1.06831 \\
\hline h.akashiwo & 7.558393 & 6.236273 \\
\hline h.circularisquama & 4.952965 & 4.918078 \\
\hline m.rubrum & 4.76163 & 2.337115 \\
\hline n.scintillans4 & 4.31307 & 4.303367 \\
\hline n.scintillans5 & 3.097148 & 2.984214 \\
\hline
\end{tabular}

\begin{tabular}{|c|l|l|} 
Mean & 3.876471 & 2.704878 \\
\hline Standard Deviation & 2.255699 & 2.126147 \\
\hline
\end{tabular}

\section{CONCLUSION}

Comparative study on discrimination methods for identifying dangerous red tide species based on wavelet utilized classification methods is conducted. Through experiments, it is found that classification performance with the proposed wavelet derived shape information extracted from the microscopic view of the phytoplankton is effective for identifying dangerous red tide species among the other red tide species rather than the other conventional texture, color information.

It is clear that the proposed wavelet descriptor is effective for image retrieval and classification. It is almost $40 \%$ improvement in terms of Euclidian distance.

Normalization of features is effective to improve Euclidian distance between specie in concern and the others. The experimental results show that the Euclidian distance between Chattnella Antiqua-3 and the others are improved remarkably, around twice much longer distance.

\section{ACKNOWLEDGMENT}

The author would like to thank Mr. Yuji Yamada for his effort to conduct the experiments.

\section{REFERENCES}

[1] Duda R.O., P.E. Hart, and D.G. Stork, (2001), Pattern Classification, (Second Edition), John Wiley \& Sons Inc.

[2] Arai K. (1996), Fundamental theory for image processing, GakujutsuTosho Shuppan Publishing Co., Ltd.

[3] Séaghdha, D.O., Ann Copestake, (2009), Using lexical and relational similarity to classify semantic relations, Computational Linguistics 621629.

[4] Teh C.H. and R. T. Chin,(1988), On image analysis by the methods of moments, IEEE Trans. On Pattern Analysis and Machine Intelligence, $10,4,496-513$

[5] Taubin G. and D. B. Cooper,(1991), Recognition and Positioning of Rigid Objects Using Algebraic Moment Invariants, SPIE Conf. On Geometric Methods in Computer Vision, 1570, 175-186.

[6] Niblack W.,(1993), The QBIC Project: Querying Images By Content Using Color, Texture and Shape, SPIE Conf. On Storage and Retrieval for Image and Video Databases, 1908, 173-187.

[7] Zahn C.T., and Ralph Z. Roskies. (1972), Fourier Descriptors for Plane closed Curves. IEEE Trans. On Computer,c-21(3):269-281.

[8] Huang C.L. and D.H. Huang,(1998), A Content-based image retrieval system. Image and Vision Computing, 16:149-163.

[9] Yang H.S., S.U. Lee, K M. Lee., (1998), Recognition of 2D Object Contours Using Starting-Point-Independent Wavelet Coefficient Matching. Journal of Visual Communication and Image Representation, 9, 2, 171-181.

[10] Tieng Q.M. and W. W. Boles, (1997), Recognition of 2D Object Contours Using the Wavelet Transform Zero-Crossing Representation, IEEE Trans. on PAMI 19, 8, 1997.

[11] Grandlund H., (1972), Fourier preprocessing for hand print character recognition, IEEE Trans. on Computers, 621, 195-201.

[12] Gibbs, J. W., (1899), "Fourier Series". Nature 59, 200 and 606.

[13] Arai K. and Yasunori Terayama (2010), Polarized radiance from red tide, Proceedings of the SPIE Asia Pacific Remote Sensing, AE10-AE101-14.

[14] Arai K. et al. (1991), Takagi and Shimoda edt., Image Analysis Handbook, Tokyo Daigaku Shuppan-kai publishing. 
[15] Arai K. (1998), Methods for Image Processing and Analysis of Earth Observation Satellite Imagery Data, Morikita Shuppan Publishing Co., Ltd.

[16] Arai K. and L. Jameson (2001), Earth observation satellite data analysis based on wavelet analysis, Morikita-Shuppan Publishing Co., Ltd.

[17] Arai K. (2002), Java based Earth observation satellite imagery data processing and analysis, Morikita-Shuppan Publishing Co., Ltd.

[18] Arai, K., (2011), Visualization of 3D object shape complexity with wavelet descriptor and its application to image retrievals, Journal of Visualization, 15, 155-166.

\section{AUTHORS PROFILE}

Kohei Arai, He received BS, MS and PhD degrees in 1972, 1974 and 1982, respectively. He was with The Institute for Industrial Science, and
Technology of the University of Tokyo from 1974 to 1978 also was with National Space Development Agency of Japan (current JAXA) from 1979 to 1990. During from 1985 to 1987 , he was with Canada Centre for Remote Sensing as a Post Doctoral Fellow of National Science and Engineering Research Council of Canada. He was appointed professor at Department of Information Science, Saga University in 1990. He was appointed councilor for the Aeronautics and Space related to the Technology Committee of the Ministry of Science and Technology during from 1998 to 2000. He was also appointed councilor of Saga University from 2002 and 2003 followed by an executive councilor of the Remote Sensing Society of Japan for 2003 to 2005. $\mathrm{He}$ is an adjunct professor of University of Arizona, USA since 1998. He also was appointed vice chairman of the Commission "A" of ICSU/COSPAR in 2008. He wrote 30 books and published 332 journal papers 